\title{
Validação financeira de algoritmos de treinamento de redes neurais para predição de tendência em séries financeiras
}

\author{
Marcus V. C. Bastos* Eduardo G. Carrano** \\ Lucas S. Batista ${ }^{* *}$ \\ * Operations Research and Complex Systems Laboratory, Programa de \\ Pós-Graduação em Engenharia Elétrica, Universidade Federal de \\ Minas Gerais, MG, (e-mail: mvcbastos@gmail.com) \\ ** Operations Research and Complex Systems Laboratory, \\ Departamento de Engenharia Elétrica, Universidade Federal de Minas \\ Gerais, MG, (e-mails: egcarrano@ufmg.br, lusoba@ufmg.br)
}

\begin{abstract}
This work proposes forecasting methods based on Artificial Neural Networks (ANNs) that focus on adjusting the network weights in order to maximize the rate of correctness of the price trends of a particular asset in the financial market, as opposed to many works that minimize the error among its real and predicted values. At the same time, the proposed approach minimizes the probability of overfitting, which is a very frequent problem in ANN applications. In order to solve this problem, a multiobjective evolutionary algorithm was implemented to optimize the proposed ANN weights, instead of Backpropagation with Levenberg-Marquardt algorithm (LM), which is one of the best versions of the most used algorithm in ANN training. An evolutionary algorithm was chosen due to the discontinuity and non-differentiability of one of the objective functions of the problem. Real data that consists of 10 assets and one index from BM\&F Bovespa were used. The computational experiments carried out indicated that the proposed approach needs improvement, since it presented losses in most of the assets analyzed individually. However, it was very promising, since it generated a total percentage return on the investment portfolio higher than the one obtained by the work that inspired this article.

Resumo: Este trabalho propõe métodos de predição baseados em Redes Neurais Artificiais (RNAs) que focam em ajustar os pesos da rede de modo a maximizar a taxa de acerto das tendências dos preços de um determinado ativo do mercado financeiro, ao contrário de muitos trabalhos que minimizam o erro entre seus valores reais e previstos. Ao mesmo tempo, a abordagem proposta minimiza a probabilidade de overfitting, que é um problema muito frequente na aplicação de RNAs. Para tratar esta questão, foi implementado um algoritmo evolucionário multiobjetivo para otimização dos pesos da RNA proposta, ao invés do Backpropagation com algoritmo de Levenberg-Marquardt (LM), que é uma das melhores versões do algoritmo mais utilizado em treinamento de RNAs. Optou-se por um algoritmo evolucionário devido à descontinuidade e não diferenciabilidade de uma das funções objetivo do problema. Empregaramse dados reais de 10 ativos e mais um índice da BM\&F Bovespa. Os experimentos computacionais realizados indicaram que a abordagem proposta precisa de melhorias, uma vez que apresentou prejuízo em grande parte dos ativos analisados individualmente. No entanto, ela se mostrou bastante promissora, visto que gerou um retorno percentual total da carteira de investimentos superior ao obtido pelo trabalho que baseou o apresentado neste artigo.
\end{abstract}

Keywords: Artificial neural networks, trend, financial market, multiobjective evolutionary algorithm.

Palavras-chaves: Redes neurais artificiais, tendência, mercado financeiro, algoritmo evolucionário multiobjetivo. 


\section{INTRODUÇÃO}

A cada dia que passa o mercado financeiro ganha novos investidores, sendo estes principalmente empresas. O objetivo das empresas que entram na bolsa de valores, sejam elas de médio ou pequeno porte, é aumentar seu preço no mercado, gerando maior disponibilidade para investimentos em si mesmas. Desta forma, elas só tendem a crescer e gerar mais lucros.

Neste contexto, pesquisas direcionadas a compreender o mercado financeiro são relevantes não somente para essas empresas, mas também a todos os interessados em investir nelas. Os robôs investidores, que consistem em algoritmos em tempo real responsáveis por extrair dados, prever valores e efetuar transações de compra e venda, são uma tendência crescente nessa área devido a automatização dos investimentos, que também são realizados de forma muito mais precisa e inteligente.

O foco desta pesquisa está nos métodos de previsão, que constituem parte desses robôs; além disso, é feita também uma validação financeira da abordagem de previsão proposta, com dados reais da BM\&F Bovespa, a bolsa de valores brasileira, de modo a mostrar sua eficiência se esta fosse aplicada no mercado.

Um modelo muito utilizado na literatura (e que foi aplicado no presente trabalho) para previsão de séries financeiras é a rede neural artificial (RNA), cujas características implementadas para resolução do problema apresentado serão citadas nas próximas seções.

O grande diferencial deste trabalho em relação a outros da área é a consideração da tendência dos preços na previsão. A tendência determina a decisão do investidor em comprar ou vender determinado ativo, enquanto a minimização de erro (que é o método utilizado na grande maioria dos trabalhos na área para a previsão dos preços de ativos do mercado) tem como objetivo apenas a aproximação entre os valores real e previsto do preço em determinado dia, o que pode gerar informações equivocadas de tendência. Desta forma, o investidor pode tomar uma decisão que o prejudique financeiramente.

Além disso, busca-se diminuir (através da minimização da norma dos pesos da RNA) a probabilidade de overfitting, sendo este um problema muito comum em Redes Neurais Artificiais.

Neste contexto, este artigo propõe três versões de um método de otimização dos pesos de uma RNA baseado na maximização dos acertos de tendência dos preços de séries financeiras. Dez ativos e um índice da BM\&F Bovespa são considerados, e os resultados são comparados a um algoritmo que considera a minimização de erro na sua implementação, como o Backpropagation com algoritmo de Levenberg-Marquardt (LM), que é uma das versões mais eficientes do algoritmo Backpropagation. Assim, objetivase verificar a superioridade da consideração do fator tendência sobre a do erro.

A comparação entre os métodos é feita através de análises estatísticas dos resultados de cada um deles. Esses resultados correspondem às taxas de acerto das tendências dos preços dos ativos no período de simulação escolhido.
Por fim, realiza-se uma validação financeira, isto é, com base no que foi previsto, o algoritmo realiza uma negociação de compra ou venda e calcula o retorno financeiro gerado naquela negociação, que estará no formato de retornos percentuais.

Este artigo está organizado da seguinte forma: a Seção 2 consiste em uma análise da literatura do problema; a Seção 3 apresenta a metodologia utilizada no trabalho; os resultados são apresentados e discutidos na Seção 4; por fim, o trabalho é encerrado na Seção 5 com as conclusões e propostas de continuidade.

\section{REVISÃO DE LITERATURA}

Existem alguns desafios a serem enfrentados quando lidamos com séries financeiras. Segundo Morettin and Toloi (2006) esses tipos de séries apresentam algumas características de difícil modelagem como tendências, sazonalidade, pontos influentes (atípicos), heterocedasticidade condicional e não linearidades, dificultando a previsão.

Além disso, há o comportamento de um determinado ativo que, dia a dia, é influenciado por fatores econômicos, sociais e políticos. Por causa desse tipo de característica, existem discussões na literatura sobre a possibilidade de imprevisibilidade do mercado. Mas muitos estudos evidenciam que há padrões neste, ou seja, mesmo que seja difícil, é possível prever seu comportamento.

Como esse tipo de discussão não é o foco deste trabalho, é sugerido ao leitor, caso tenha interesse, que veja os estudos analisados em Nametala (2017).

Existem vários métodos de inteligência computacional que são aplicados neste problema, como preditores econométricos e técnicas que utilizam RNAs, normalmente, por meio da minimização de erro no processo de treinamento, como apresentado em Nametala (2017) e Patel and Marwala (2006). Ambos os trabalhos aplicam redes neurais na previsão de preços de fechamento, mas Nametala (2017) utiliza um método híbrido, com dados da BM\&F Bovespa, combinando RNAs do tipo MLP e preditores econométricos. Por outro lado, Patel and Marwala (2006) prevê dados dos índices Dow Jones, Johannesburg Stock Exchange All Share, Nasdaq 100 e Nikkei 225, empregando redes neurais do tipo RBF e MLP.

Algoritmos evolucionários multiobjetivo, como o descrito no presente artigo, também são utilizados no treinamento de RNAs para previsão de séries temporais (Du et al., 2014; Cuéllar et al., 2005). O algoritmo NSJADE (Du et al., 2014) tem a função de otimizar a topologia junto com a norma dos pesos da camada escondida da rede, enquanto o método proposto em Cuéllar et al. (2005) busca otimizar somente sua topologia.

O trabalho corrente é baseado em Nametala (2017) no que diz respeito à escolha dos ativos e ao tratamento feito com seus dados. No entanto, este apresenta um modelo mais simples e utiliza uma abordagem que explora as tendências dos preços, ao invés da minimização de erro.

\section{METODOLOGIA}

Nesta seção são descritos os dados e métodos utilizados no trabalho. 
A RNA utilizada foi uma rede feedforward, MLP, com cinco entradas, uma camada escondida contendo 15 neurônios com função de ativação Sigmoide Logarítmica, e uma camada de saída com apenas um neurônio com função de ativação linear.

Os dados de entrada dessa rede consistem nos preços de abertura, máxima, mínima, fechamento e no volume de negociações, que são valores presentes nas séries financeiras e são fundamentais para determinar uma cotação.

Os dados empregados neste trabalho para as previsões correspondem aos valores mencionados no parágrafo anterior de 10 ativos mais o índice Bovespa (BOVA 11) da bolsa de valores brasileira BM\&F Bovespa. Esses dados estão contidos no período entre 02/01/2009 e 30/12/2013. Foram considerados os mesmos ativos de Nametala (2017).

O processo de previsão foi executado utilizando-se a técnica de janelamento móvel presente em Gambogi (2013) e Kaastra and Boyd (1996).

Buscando diminuir ruídos das entradas da rede neural e minimizar o tempo de processamento, foi implementada uma técnica que transforma os dados no logaritmo dos seus retornos. Este método foi aplicado também em Miranda et al. (2012).

O algoritmo de treinamento da RNA usada para resolução do problema apresentado neste trabalho se trata do Differential Evolution for Multiobjective Optimization (DEMO). Este algoritmo foi escolhido devido à suas vantagens em problemas de otimização biobjetivo (Bandyopadhyay and Mukherjee, 2015).

Os objetivos escolhidos para este problema foram a métrica Percentage of Change in Direction (POCID), aplicada nesta pesquisa segundo Azevedo (2014), e a norma do vetor de pesos da rede, sendo que este vetor representa cada indivíduo da população do DEMO. A Equação (1) mostra a formulação do POCID:

$$
\begin{gathered}
\text { POCID }=\frac{1}{N} \sum_{i=1}^{N} a_{i}, \text { onde } \\
\left\{\begin{array}{l}
a_{i}=1, \text { se }\left(y_{i}-y_{i-1}\right)\left(r_{i}-r_{i-1}\right)>0 \\
a_{i}=0, \text { se }\left(y_{i}-y_{i-1}\right)\left(r_{i}-r_{i-1}\right) \leq 0
\end{array},\right.
\end{gathered}
$$

onde $y_{i}$ diz respeito ao valor previsto e $r_{i}$ ao valor real dos preços de fechamento presentes no conjunto de dados.

O POCID apresenta valores que variam no intervalo $[0,1]$, sendo que quanto mais próximo de 1 , maior o número de acertos das tendências dos preços de fechamento previstos em relação às dos preços reais. Se multiplicado por 100 , o POCID se torna a taxa de acerto dessas tendências.

Cada indivíduo da população do algoritmo DEMO foi representado conforme (2):

$$
x=\left[\begin{array}{c}
w_{1, i, n} \\
w_{2, n}
\end{array}\right],
$$

onde o primeiro índice é o número da camada (1 é a camada escondida e 2 a de saída), $i$ corresponde ao número de entradas e varia de 1 a 5 , enquanto $n$ representa cada neurônio da camada escondida da RNA. Portanto, este índice varia de 1 a 15. Com esta definição, é possível concluir que cada indivíduo $x$ tem dimensão $90 \mathrm{x} 1$.

O tamanho da população escolhido para o algoritmo foi 50 , o critério de parada corresponde ao número máximo de iterações, definido como 300. A probabilidade de recombinação e o fator de escala selecionados foram 0.8 e 0.9 , respectivamente. Os parâmetros adotados foram definidos de forma arbitrária. O estudo e ajuste dos mesmos não foi considerado no escopo deste trabalho.

Um dos desafios na implementação do algoritmo de treinamento consistiu na inicialização da população inicial de pesos. Logo, optou-se por utilizar o algoritmo de NguyenWidrow Nguyen and Widrow (1990), devido à sua eficiência e velocidade de execução em testes utilizando o Backpropagation com algoritmo de Levenberg-Marquardt para treinamento da rede de mesma arquitetura da aplicada neste trabalho.

Após o treinamento, o DEMO retorna um conjunto de vetores de pesos correspondentes à fronteira Pareto estimada. Na sequência, o melhor deles é posteriormente inserido na rede neural para que sejam feitas as próximas previsões. O resultado final do algoritmo consiste em um valor de POCID para 100 previsões no período entre 2012 e 2013. O dia inicial para cada execução é escolhido de forma aleatória neste período, seguindo uma distribuição uniforme.

Apesar de apenas um método para escolha do vetor de pesos a ser utilizado no processo de previsão ser escolhido para a validação financeira, todos são descritos nas próximas subseções da forma mais detalhada possível, de forma a mostrar diferentes maneiras de resolver o problema e apresentar qual delas funciona melhor, uma vez que isso pode abrir espaço para o surgimento de novos métodos que podem ser ainda mais eficientes que os retratados neste artigo.

\subsection{Comitê de soluções}

A esta técnica foi dado o nome $M_{1}$, e recebe como entrada os preços de fechamento previstos após o treinamento com o DEMO (desnormalizados e convertidos em valores absolutos) e os valores reais correspondentes.

Considerando-se esses dados, realiza-se um comitê com todas as soluções da fronteira Pareto estimada, a partir do qual será definida a tendência que a previsão de um determinado dia gerou, onde esta deve corresponder a uma categoria dentre três: subida, descida e estabilidade.

Um exemplo desta abordagem está ilustrado na Figura 1. Cada ponto representa o valor de função de um vetor de pesos a partir do qual são previstos os preços de fechamento. Esses preços são comparados aos reais para que seja verificada a tendência. Desse modo, cada ponto adquire um valor de tendência dentre os três tipos citados anteriormente. Vence a tendência que teve o maior número de ocorrências dentre os pontos da fronteira; no caso da Figura 1, foi a tendência "descida". No exemplo, é possível perceber que o método obteve um acerto, visto que o preço real do dia 1 para o dia 2 também caiu. Isso é repetido a cada previsão feita antes do deslocamento da janela corrente, contando os acertos que ocorrem. 


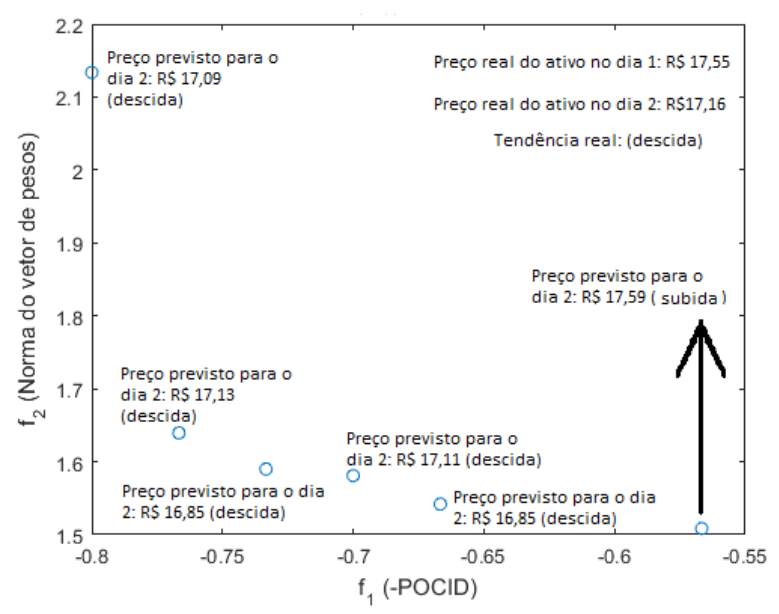

Figura 1. Método M1 em um exemplo de fronteira Pareto

O que determina qual tipo de tendência é gerada por um certo preço previsto é se a diferença entre este e o preço real do dia anterior está à direita (subida), à esquerda (descida) ou dentro de um intervalo especificado (estabilidade). Os seus limiares são determinados pela taxa de corretagem por ordem, definida como $\mathrm{R} \$ 3,80$; e são calculados de acordo com (3) e (4).

Este valor para a taxa de corretagem foi selecionado levando-se em conta um levantamento realizado junto a três corretoras nacionais para pacotes de transação com 1000 ordens. Tomou-se o preço mais alto encontrado entre elas, como determinado em Nametala (2017).

$$
\begin{gathered}
L_{1}=-\frac{3,80}{(100 * \text { lotes })}=-\frac{3,80}{500}=-0,0076 \\
L_{2}=\frac{3,80}{(100 * \text { lotes })}=\frac{3,80}{500}=0,0076
\end{gathered}
$$

$L_{1}$ e $L_{2}$ são os extremos do intervalo e lotes corresponde ao número de lotes que podem ser negociados em uma operação. Este foi definido com o valor 5 apenas para fins de simulação.

Como exemplo, calcula-se a diferença entre o preço previsto através do vetor de pesos, representado pelo primeiro ponto (da esquerda para a direita) da fronteira Pareto da Figura 1, e o preço real do dia anterior:

$$
17,09-17,55=-0,46<L_{1},
$$

ou seja, para este ponto, a tendência é de descida, como indicado nesta figura.

Se em uma execução de $M_{1} 100$ previsões são feitas, e o mesmo avaliou que acertou a tendência em 55, este valor é dividido por 100 para que fique no mesmo formato da métrica POCID.

\subsection{Utilização de três conjuntos de dados}

Neste método de decisão, chamado de $M_{2}$, considera-se os conjuntos de treinamento, validação e teste.
O conjunto de treinamento é uma janela de tamanho 30, onde o algoritmo DEMO é executado, gerando as soluções Pareto estimadas.

O conjunto de validação é outra janela de tamanho 10 (que começa no dia seguinte ao último dia da janela do conjunto de treinamento), onde mais previsões usando cada solução Pareto aproximada são realizadas. Os preços resultantes dessas previsões são avaliados quanto ao POCID. A solução que gerou o maior POCID é escolhida como a que será utilizada na parte de teste. Caso ocorra empate, escolhe-se a solução que produzir a menor norma dos pesos.

O conjunto de teste é o último deste método e apresenta uma janela de tamanho 10 (começando no dia seguinte ao último dia da janela do conjunto de validação). Os preços presentes no candle e o volume desse conjunto são inseridos na entrada da rede neural, e contém os valores de pesos retornados pela execução da parte do método relacionada ao conjunto de validação. Com isso, são feitas as previsões e o POCID resultante é calculado.

Vale ressaltar que, com o que foi descrito nos parágrafos sobre o conjunto de treinamento e validação, percebe-se que na realidade, a rede está sendo treinada com uma janela de 40 dias. A diferença é que os dados do conjunto de validação não foram considerados no treinamento usando o DEMO, então, caso os valores resultantes da primeira parte deste método estejam "overfitados", a segunda parte pode encontrar soluções mais interessantes antes que a verdadeira previsão (que será feita através do conjunto de teste) ocorra. Isto é, este método tenta diminuir ainda mais a probabilidade de overfitting que pode ocorrer com o treinamento da rede, além de refinar o processo de decisão da melhor solução da fronteira Pareto estimada.

\subsection{Programação de compromissos}

Este método foi definido no presente artigo como $M_{3}$ e trata-se de uma técnica de análise de decisão multicritério, que visa indicar a melhor solução de compromisso para um problema de otimização com mais de um objetivo. No método é identificada a solução, dentre as presentes na fronteira Pareto estimada, que está mais perto da solução utópica, ou ideal, mediante o uso de uma medida de proximidade (Lee and Li, 1993), chamada neste artigo de desvio. As formulações da solução ideal e do desvio empregados estão representadas em (5) e (6), respectivamente.

$$
\mathbf{f}^{*}=\left[f_{1}^{*}, \ldots, f_{i}^{*}, \ldots, f_{m}^{*}\right]
$$

onde $m$ corresponde ao número de objetivos e $f_{i}^{*}$ ao melhor valor individual de função para cada objetivo $i$ do problema.

$$
d_{j}=\left[\sum_{i=1}^{m} w_{i} \frac{\left|f_{i}\left(x_{j}\right)-f_{i}^{*}\right|^{r}}{\tilde{f}_{i}-f_{i}^{*}}\right]^{1 / r},
$$

onde $f_{i}^{*}$ é a solução utópica para o objetivo $i, \tilde{f}_{i}$ é a solução anti-utópica para o objetivo $i, f_{i}\left(x_{j}\right)$ é o valor de função correspondente a cada solução $j$ da fronteira Pareto estimada (espaço de objetivos), $r$ é o valor da norma, no caso deste trabalho seu valor é $2, w_{i}$ é o valor dos pesos de cada objetivo, definidos como 0.6 no caso do primeiro (POCID), e 0.4 quanto ao segundo objetivo (norma dos 
pesos), $m$ é o número de objetivos, no caso deste trabalho $m=2$ e $d_{j}$ é o desvio daquela solução $j$ em relação à solução utópica.

A melhor solução de compromisso é aquela que apresentar o menor desvio.

\subsection{Backpropagation com algoritmo de Levenberg-Marquardt}

Como mencionado na Seção 1 o algoritmo que utiliza minimização de erro escolhido para comparação com os métodos propostos foi o Backpropagation com algoritmo de Levenberg-Marquardt. Ele foi implementado para treinamento da rede utilizando o pacote $S N N S$ do $\mathrm{R}$ com os parâmetros descritos na Tabela 1.

Foi considerado um valor máximo de 30000 épocas no treinamento para que o mesmo pudesse ser eficaz, uma vez que não se sabe o número ideal de épocas para todos os ativos usados e o índice Bovespa.

Alguns testes em algumas séries financeiras foram realizados com esses parâmetros, levando à conclusão de que o erro era minimizado na fase de teste. Ou seja, não houve overfitting com esse número de épocas no algoritmo LM. Dessa forma, 30000 épocas foi um valor máximo aceitável.

Os demais parâmetros foram selecionados através dos valores sugeridos pelo manual do pacote.

\section{RESULTADOS}

O experimento de comparação realizado consiste em duas etapas: onze análises estatísticas dos ativos individuais, e uma análise conjunta, para que seja possível analisar a presença de uma certa consistência entre os resultados de ambas as etapas. Na sequência, o método proposto que apresentar melhor desempenho será utilizado na validação financeira.

Os dados para tal experimento foram coletados através de 112 execuções do algoritmo de previsão para cada ativo em cada método a ser comparado, totalizando 4928 execuções. Com isso, o tamanho amostral da primeira etapa é igual a 112 e o da segunda etapa é igual a 1232. É importante ressaltar que todas as amostras em cada etapa estão balanceadas, ou seja, o número de observações em cada grupo é o mesmo.

O one-way ANOVA foi utilizado para os testes de hipóteses. A função usada para sua implementação foi a anova, que está presente no pacote stats do R.

Após a execução do one-way ANOVA foi possível concluir, em todas as etapas do experimento, que a hipótese nula deveria ser rejeitada, isto é, com $95 \%$ de confiança, existe uma diferença significativa nas médias de desempenho entre os métodos.

Porém, o one-way ANOVA não é capaz de gerar um ranking dos métodos comparados, logo, foi preciso aplicar o teste de Tukey, através do pacote multcomp do R.

Para utilizar o one-way ANOVA e o teste de Tukey, devese atender à algumas premissas quanto ao comportamento dos resíduos do modelo estatístico, como: (1) independência; (2) normalidade, ou seja, os resíduos devem seguir $\mathbf{9 5} \%$ family-wise confidence level

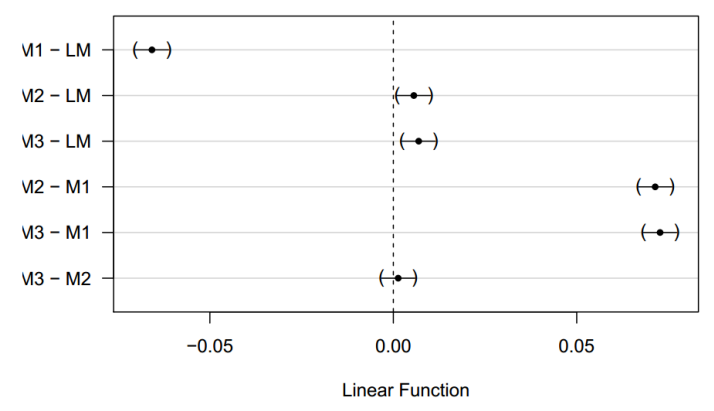

Figura 2. Resultado do teste de Tukey (All vs. all)

uma distribuição normal; e (3) homoscedasticidade, isto é, igualdade de variâncias entre os grupos. Após a realização de alguns testes estatísticos específicos para verificação dessas premissas, concluiu-se que todas foram atendidas.

\subsection{Resultados das análises por ativo}

Os rankings gerados pela execução do teste de Tukey para cada ativo são, com $95 \%$ de confiança:

$\begin{array}{ll}\text { BBAS3: } \overline{M_{2} M_{3} L M} M_{1} & \text { GGBR4: } \overline{M_{2} M_{3} L M} M_{1} \\ \text { BBDC4: } \overline{M_{2} M_{3} L M} M_{1} & \text { ITSA4: } \overline{M_{2} M_{3} L M} M_{1} \\ \text { BOVA11: } \overline{M_{2} M_{3} L M} M_{1} & \text { PETR4: } \overline{M_{2} M_{3} L M} M_{1} \\ \text { BVMF3: } \overline{M_{2} M_{3} L M} M_{1} & \text { USIM5: } \overline{M_{2} M_{3} L M} M_{1} \\ \text { CSNA3: } \overline{M_{2} M_{3}} L M M_{1} & \text { VALE5: } \overline{M_{2} M_{3} L M} M_{1}\end{array}$

\subsection{Resultados da análise conjunta}

A mesma análise estatística anterior foi repetida, porém os dados utilizados foram os de todos os ativos em conjunto.

Como na etapa anterior foram feitos vários testes de hipóteses e várias análises, não seria viável colocar todas as informações gráficas neste artigo, mas nesta etapa, apenas uma análise estatística foi executada, portanto será mostrado o gráfico correspondente ao resultado do teste do Tukey, presente na Figura 2.

A partir da análise destas informações, conclui-se que o ranking dos métodos é: $\overline{M_{2} M_{3}} L M M_{1}$.

Nota-se a partir deste resultado, que além de todas as análises apresentarem consistência umas com as outras, o fato do tamanho amostral na análise conjunta ser muito maior do que o da análise por ativo, ocasionou em uma maior precisão do ranking dos métodos, indicando que as técnicas propostas $M_{2}$ e $M_{3}$ apresentam melhor desempenho em média do que o algoritmo $L M$, apesar das diferenças serem, aproximadamente, de $0,6 \%$ apenas (em ambos os casos), de acordo com seus estimadores pontuais apresentados na Figura 2.

Buscando facilitar o processo de validação financeira, que será apresentado na próxima subseção, foi escolhido apenas um método dentre os propostos para resolução do problema do trabalho.

A técnica $M_{2}$ foi selecionada por ser uma estratégia original de tomada de decisão pensada especificamente 
Tabela 1. Parâmetros do algoritmo LM

\begin{tabular}{|c|c|}
\hline Característica & Valor \\
\hline Máximo de épocas & 30000 \\
\hline Intervalo de aleatorização dos pesos sinápticos & {$[-0.3 ; 0.3]$} \\
\hline Função nos neurônios da camada escondida & Logística Sigmoide \\
\hline$\sigma_{1}$ & $10^{-4}$ \\
\hline$\lambda_{1}$ & $10^{-6}$ \\
\hline Precisão & $10^{-16}$ \\
\hline
\end{tabular}

para o problema deste trabalho, além de ter sido a que apresentou melhor desempenho no processo de predição, juntamente com $M_{3}$.

Logo, a partir deste ponto do artigo, sempre que for mencionada a solução proposta ou o modelo proposto, este representa a RNA com o método $M_{2}$ implementado.

\subsection{Validação financeira}

A validação financeira deste trabalho se dará através dos cálculos dos retornos financeiros gerados pelas negociações que tiveram como base os resultados da predição.

O algoritmo de negociação funciona da seguinte forma: Se o preço de um determinado ativo está previsto para subir no dia seguinte ao dia corrente considerado no treinamento, então o algoritmo de negociação executa uma compra e, se o preço realmente subiu, foi uma compra que gerou lucro, senão, houve prejuízo. Analogamente, o mesmo acontece caso o preço caia, porém, a operação que o algoritmo executa é de venda. Se o preço não aumenta e nem diminui, o algoritmo não realiza nenhuma operação, não ocorrendo lucro ou prejuízo para o investidor.

Os retornos financeiros tratam da magnitude de ganhos ou perdas obtidas pelo modelo deste trabalho durante o período de simulação em moeda brasileira $(\mathrm{R} \$)$.

Esses resultados dizem respeito a 494 dias de pregão situados no período que vai de 02/01/2012 a 30/12/2013. Em todos os experimentos foram utilizados 5 lotes de 100 ações (500 ações). Quanto a taxa de corretagem por ordem, quando esta foi considerada, utilizou-se o valor de $\mathrm{R} \$ 3,80$. Este custo foi selecionado levando-se em conta um levantamento realizado em 2016 por Nametala (2017) junto a três corretoras nacionais para pacotes de transação com 1000 ordens. Tomou-se o preço mais alto encontrado entre estas.

De modo a tornar os cálculos de retornos financeiros deste trabalho os mais próximos possíveis da realidade, considerou-se as mesmas taxas praticadas pelo mercado financeiro utilizadas por Nametala (2017). Os resultados finais são apresentados no formato de retornos percentuais na Tabela 2.

Apresenta-se também nesta tabela os retornos sem as taxas, de modo que o leitor possa perceber o impacto causado por elas no lucro ou no prejuízo do investidor. Fica nítido que as taxas do mercado influenciam fortemente nos rendimentos, neste caso, evidenciando uma queda de $312,14 \%$ para $216,88 \%$ no retorno percentual total, ou seja, uma perda de cerca de $30 \%$ no desempenho médio.

É interessante observar que a RNA, para o ativo BBDC4, se mostrou tão lucrativa que mesmo com os prejuízos gera- dos na maioria dos ativos da carteira, o retorno percentual total considerando-se todas as taxas foi significativamente superior ao obtido em Nametala (2017), sendo este igual a $71,02 \%$.

Deste modo, o elevado lucro gerado nas negociações desse ativo compensou os prejuízos encontrados em vários dos ativos da carteira, mesmo com a subtração de todas as taxas existentes em operações no mercado, ocasionando no valor total de retorno positivo citado anteriormente.

Tabela 2. Retornos percentuais para análises sem e com todas as taxas de operação considerando-se o algoritmo $M_{2}$

\begin{tabular}{|c|c|c|}
\hline Ativo & $\begin{array}{c}\text { Retornos } \\
\text { percentuais } \\
\text { sem taxas }\end{array}$ & $\begin{array}{c}\text { Retornos } \\
\text { percentuais } \\
\text { com taxas }\end{array}$ \\
\hline BBAS3 & $-52.95 \%$ & $-106,63 \%$ \\
\hline BBDC4 & $3431,56 \%$ & $2839,03 \%$ \\
\hline BOVA11 & $57,60 \%$ & $34,21 \%$ \\
\hline BVMF3 & $-25,59 \%$ & $-123,66 \%$ \\
\hline CSNA3 & $-23,70 \%$ & $-93,77 \%$ \\
\hline CYRE3 & $-22,86 \%$ & $-83,64 \%$ \\
\hline GGBR4 & $25,43 \%$ & $-35,93 \%$ \\
\hline ITSA4 & $-67,03 \%$ & $-214,12 \%$ \\
\hline PETR4 & $6,26 \%$ & $-34,98 \%$ \\
\hline USIM5 & $7,76 \%$ & $-69,57 \%$ \\
\hline VALE5 & $25,05 \%$ & $-5,19 \%$ \\
\hline TOTAL & $312,14 \%$ & $216,88 \%$ \\
\hline
\end{tabular}

Fazendo-se agora uma análise comparativa entre a solução proposta e uma RNA de mesma arquitetura da implementada para este trabalho, porém com o algoritmo LM utilizado no treinamento (RNALM), podem ser observados os resultados da Tabela 3 .

Tabela 3. Retornos percentuais para análises sem e com todas as taxas de operação considerando-se o algoritmo LM

\begin{tabular}{|c|c|c|}
\hline Ativo & $\begin{array}{c}\text { Retornos } \\
\text { percentuais } \\
\text { sem taxas }\end{array}$ & $\begin{array}{c}\text { Retornos } \\
\text { percentuais } \\
\text { com taxas }\end{array}$ \\
\hline BBAS3 & $93,16 \%$ & $33,10 \%$ \\
\hline BBDC4 & $-21,85 \%$ & $-69,22 \%$ \\
\hline BOVA11 & $-11,84 \%$ & $-27,90 \%$ \\
\hline BVMF3 & $21,10 \%$ & $-76,20 \%$ \\
\hline CSNA3 & $-15,48 \%$ & $-84,23 \%$ \\
\hline CYRE3 & $-23,91 \%$ & $-84,86 \%$ \\
\hline GGBR4 & $-50,33 \%$ & $-115,73 \%$ \\
\hline ITSA4 & $-14,21 \%$ & $-152,75 \%$ \\
\hline PETR4 & $-57,29 \%$ & $-106,74 \%$ \\
\hline USIM5 & $-20,92 \%$ & $-100,39 \%$ \\
\hline VALE5 & $26,40 \%$ & $-4,06 \%$ \\
\hline TOTAL & $-5,36 \%$ & $-48,29 \%$ \\
\hline
\end{tabular}

Nota-se por essa tabela que a RNALM gerou prejuízos na grande maioria dos ativos. Se consideradas todas as taxas 
Tabela 4. Comparação entre os retornos percentuais, sem inclusão de taxas, pertencentes a RNALM e a RNA de Candles implementada por (Nametala, 2017)

\begin{tabular}{|c|c|c|}
\hline Ativo & RNALM & RNA Candles \\
\hline BBAS3 & $93,16 \%$ & $141,99 \%$ \\
\hline BBDC4 & $-21,85 \%$ & $120,95 \%$ \\
\hline BOVA11 & $-11,84 \%$ & $51,81 \%$ \\
\hline BVMF3 & $21,10 \%$ & $8,61 \%$ \\
\hline CSNA3 & $-15,48 \%$ & $106,02 \%$ \\
\hline CYRE3 & $-23,91 \%$ & $87,19 \%$ \\
\hline GGBR4 & $-50,33 \%$ & $2,95 \%$ \\
\hline ITSA4 & $-14,21 \%$ & $107,53 \%$ \\
\hline PETR4 & $-57,29 \%$ & $69,78 \%$ \\
\hline USIM5 & $-20,92 \%$ & $-6,98 \%$ \\
\hline VALE5 & $26,40 \%$ & $43,12 \%$ \\
\hline
\end{tabular}

no cálculo dos retornos é possível perceber que apenas 1 ativo não gerou prejuízo e que o investimento na carteira ocasionou um prejuízo de 48,29\%.

A Tabela 4 faz uma comparação entre a RNALM e uma RNA de mesma arquitetura e variáveis de entrada implementada por Nametala (2017), onde foram realizadas técnicas de adaptação da topologia da rede utilizando informações de previsões passadas.

Os prejuízos gerados pelo modelo proposto e pela RNALM, na grande maioria dos ativos, mostram a importância da utilização das informações de taxa de acerto e dos rendimentos obtidos até o presente momento para otimizar as previsões futuras (através de realimentação da rede neural). Mostram-se importantes também a implementação de métodos que buscam maximizar lucros com a definição de pontos de stops e takeprofits, uma vez que tais técnicas, assim como todas as outras citadas neste parágrafo, foram implementadas em Nametala (2017) e geraram bons resultados, tanto o robô implementado em seu trabalho quanto a RNA de Candles aplicada por ele.

No entanto, o objetivo deste trabalho não é gerar bons rendimentos financeiros e sim analisar se existe superioridade na utilização do fator tendência das séries financeiras para a predição ao invés da minimização de erro. A geração de bons rendimentos financeiros neste caso é mera consequência do desempenho da solução proposta. Logo, não foi de interesse deste trabalho o emprego de métodos mais sofisticados para maximização dos lucros.

\section{CONCLUSÕES}

A preocupação em diminuir os riscos e aumentar os retornos com operações no mercado financeiro através de estratégias eficientes cresce cada vez mais. Nesse sentido, qualquer contribuição que venha diminuir a lacuna entre teoria e experimentação neste campo é válida, dado que o comportamento do mercado é algo muito complexo, visto que os bens negociados tendem a sofrer as mais diversas influências.

Com as adaptações necessárias este trabalho poderia contribuir com outras áreas, uma vez que pode ser aplicado em séries temporais com características semelhantes às financeiras.
Percebe-se que a abordagem proposta neste trabalho, que visa a maximização dos acertos de tendência dos preços de séries financeiras é bastante promissora (principalmente a solução $M_{2}$ ), visto que apresentou bom desempenho se comparada a outros trabalhos da área. Isso mostra que a consideração do fator tendência não somente cumpre seu papel na predição do comportamento do mercado e na obtenção de bons retornos, mas também tem potencial para ser muito melhor do que as técnicas baseadas em minimização de erro usualmente aplicadas na área. Desta forma, pode-se dizer que o principal objetivo do trabalho foi atendido.

Como proposta de continuidade da pesquisa deste trabalho, sugere-se o levantamento de novas hipóteses, e a realização de mais experimentos que busquem compreender o motivo pelo qual os resultados das negociações do ativo BBDC4 diferiram tanto dos outros. Por se tratarem de sistemas caixa preta, as Redes Neurais dificultam esse tipo de análise, e isso associado à complexidade do mercado foi determinante para que essas atividades não estivessem no escopo do presente trabalho. Esse tipo de análise pode ajudar a descobrir se o problema se encontra na seleção dos ativos, nos algoritmos de treinamento ou negociação, no método de tomada de decisão, ou em outros pontos da solução.

A implementação de um robô investidor com a utilização de técnicas que exploram a tendência dos preços se trata de uma abordagem muito importante, assim como a análise descrita no parágrafo anterior, para descobrir maneiras de melhorar o método proposto, uma vez que mais comparações com outros trabalhos da área podem ser feitas e mais dados podem ser coletados.

Se a solução proposta tivesse toda a robustez de um robô investidor, utilizando realimentação de redes neurais com informações de tendência dos preços em tempo real, otimização dinâmica da sua topologia, implementação de um conjunto de técnicas de negociação ao invés de uma mais simplificada, como a apresentada neste artigo, e uma estratégia diferente de escolha dos ativos a serem negociados, os retornos gerados poderiam ser muito melhores, visto que a consideração da tendência dos preços no algoritmo de treinamento apresentou resultados excelentes se comparados aos do modelo que utiliza minimização de erro, como discutido no presente trabalho. Dessa forma, a aplicação dessa solução mais sofisticada no mercado seria viável.

\section{AGRADECIMENTOS}

Este trabalho recebeu apoio da PRPq/UFMG e das seguintes agências de fomento brasileiras: FAPEMIG, CAPES e CNPq (404988/2016-4).

\section{REFERÊNCIAS}

Azevedo, C.R.B. (2014). Anticipation in Multiple Criteria Decision-Making Under Uncertainty. Ph.D. thesis, Universidade Estadual de Campinas.

Bandyopadhyay, S. and Mukherjee, A. (2015). An algorithm for many-objective optimization with reduced objective computations: A study in differential evolution. IEEE Transactions on Evolutionary Computation. 
Cuéllar, M., Calvo-Flores, M., and Pegalajar Jiménez, M.d.C. (2005). Multiobjective evolutionary optimization for elman recurrent neural networks, applied to time series prediction. X, 17-33.

Du, W., Leung, S.Y.S., and Kwong, C.K. (2014). Time series forecasting by neural networks: A knee pointbased multiobjective evolutionary algorithm approach. Expert Systems with Applications.

Gambogi, J.A. (2013). Aplicação de Redes Neurais na Tomada de Decisão no Mercado de Ações. Master's thesis, Universidade de São Paulo.

Kaastra, I. and Boyd, M.S. (1996). Designing a neural network for forecasting financial and economic time series. Neurocomputing, 10, 215-236.

Lee, E.S. and Li, R. (1993). Fuzzy multiple objective programming and compromise programming with pareto optimum. Fuzzy Sets and Systems, 53(3), 275 - 288.

Miranda, A., Ceretta, P.S., and Lopes, L.F.D. (2012). Estratégias de mercado acionário utilizando previsão de redes neurais em comparação com modelos autorregressivos. Revista da Administração, 8(1), 42-59.

Morettin, P.A. and Toloi, C. (2006). Análise de Séries Temporais. Blucher, São Paulo, $2^{\mathrm{a}}$ edition.

Nametala, C.A.L. (2017). Construção de um Robô Investidor baseado em Redes Neurais Artificiais e Preditores Econométricos. Master's thesis, Universidade Federal de Minas Gerais.

Nguyen, D. and Widrow, B. (1990). Improving the learning speed of 2-layer neural networks by choosing initial values of the adaptive weights. Proceedings of the International Joint Conference on Neural Networks, 3 , 21-26.

Patel, P.B. and Marwala, T. (2006). Forecasting closing price indices using neural networks. IEEE Conference on Systems, Man and Cybernetics. 